\title{
Embryonic stem cells and tissue engineering: delivering stem cells to the clinic
}

\author{
A Vats FRCS ${ }^{1,2} \quad$ N S Tolley FRCS ${ }^{2} \quad$ A E Bishop PhD ${ }^{1} \quad J^{M}$ Polak DBE FRCPath ${ }^{1}$
}

J R Soc Med 2005;98:346-350

One of the challenges facing biomedical science is of its own making - namely, the progressive increase in lifespans. An increasing number of individuals require treatment and the treatments themselves have to work for longer. A shift in emphasis is therefore required towards biological approaches including the regeneration of tissues. Tissue engineering can be best defined by its goal — the design and construction in the laboratory of living components that can be used for the maintenance, repair or replacement of malfunctioning tissues. In this discipline, born in 1933 when tumour cells were wrapped in a polymer membrane and implanted into a pig, ${ }^{1}$ the life sciences and medicine come together with engineering in activities centred on three basic components - cells, scaffolds and signals. The development of tissue engineering has lately been spurred by the increased availability of cell sources, proteomics, the advent of new biomaterials, improvements in bioreactor design and increased understanding of healing. However, neither commercial development nor clinical application of tissue engineered products has kept pace with this rapidly evolving research. Industrial development has been hindered by difficulties in devising cost-efficient processes, guaranteeing product viability and satisfying the regulators. Nevertheless, the coming years will see a large increase in the number of patients benefiting from tissue engineering. For the cell biology component of tissue engineering, the greatest challenge is to optimize the isolation, proliferation and differentiation of cells and to design scaffolds or delivery systems that yield tissue growth in three dimensions. Ideally, we would harvest stem cells from a patient, expand them in cell culture, seed them on a scaffold and then implant the resultant tissue. Stem cells, when given the specific biological stimuli, can differentiate to become many types of specific mature cells, and use of these cells avoids the immunorejection that can occur with donor transplants. In addition, the technique of somatic nuclear transfer allows the creation of autologous cells and tissues from allogeneic embryonic stem cells. It is then

${ }^{1}$ Tissue Engineering and Regenerative Medicine Centre, Faculty of Medicine, Imperial College London, Chelsea \& Westminster Hospital, 369 Fulham Road, London SW10 9NH; '2St Mary's Hospital, Praed Street, London W2 1NY, UK important for the scaffold to act as a template and stimulus for proliferation and differentiation of the stem cells into the mature cells that will generate specific new tissue. The tissue can be grown on a scaffold that will resorb, so that only the new tissue will be implanted, or a 'biocomposite' of the scaffold and new tissue can be implanted. After implantation, the tissue-engineered construct must be able to survive, restore normal function and integrate with the surrounding tissues.

\section{CELL SOURCES}

The success of tissue engineering depends on the generation of appropriate cells and the ability of those cells to perform specific biological functions. For example, cells must produce extracellular matrix in the correct organization, secrete cytokines and other signalling molecules, and interact with neighbouring cells/tissues. Tissue engineers have, over the years, looked at virtually all tissues in the body. In some cases, it has been possible to repair/replace tissue using, as a starting material, the relevant cells from the same patient - such as knee repair with autologous chondrocytes. ${ }^{2}$ Non-specific cell types have also been used, including dermal fibroblasts for heart valve engineering. ${ }^{3}$ These early cell sources had severe limitations, including low yield and the possibility of gene alterations related to age. Although primary (especially autologous) cells are still used in tissue engineering, stem cells constitute an important new resource.

Stem cells are commonly defined as undifferentiated cells that have the capacity both to self-renew and to differentiate into one or more types of specialized cells; however, this definition has required reconsideration in view of the observation of dedifferentiation and transdifferentiation of certain mature cells. ${ }^{4-6}$ Therefore, some workers now favour a broader definition, applicable to a biological function that can be induced in a range of cell types, including differentiated cells, rather than a single entity. ${ }^{7}$ Current sources of stem cells for tissue engineering include embryos and adult donors. The range of cell types to which they can differentiate varies, with embryonic stem cells the most pluripotent. For tissue engineering, stem cells can provide a virtually inexhaustible cell source. Current research is focused on promoting stem cell 
differentiation to required lineages, purification of consequent cells, confirmation that there is no residual carcinogenic potential in the cell population and implantation in a form that will replace or augment the function of diseased or injured tissues. ${ }^{8,9}$ Both types of stem cell, embryonic and adult, have drawbacks. With embryonic stem cells there are ethical considerations, together with the possibility of tumorigenicity; also, not many cell lines are available. Adult stem cells are more limited in potential and are often difficult to harvest in sufficient numbers. Thus, the search continues for an ethically non-controversial, easily accessible and abundant source of stem cells. The discussion here focuses on embryonic stem cells.

\section{Embryonic stem cells}

Pluripotent stem cells can be divided into three typesembryonic germ cells derived from primordial germ cells, embryonic stem cells and embryonic carcinoma cells. The usual view is that these cells are able to differentiate into all cells that arise from the three germ layers but not the embryo; however, this dogma has been challenged by the discovery that embryonic stem cells can differentiate to trophoblast cells in vitro. ${ }^{10}$

The identification and isolation of embryonic stem (ES) cells from the mouse, by Evans and Kaufman, was a major event in biology. ${ }^{11,12}$ From the early 1950s, the work of Stevens and Pierce (reviewed by Alexandre ${ }^{13}$ ) had shown that teratocarcinomas contain cells with multilineage potential. The isolation and culture of embryonal carcinoma (EC) cells gave developmental biologists an in-vitro model with which to study the processes of differentiation. ${ }^{14}$ The isolation of ES cells from first primate ${ }^{15}$ and then human blastocytes $^{16}$ was the step that put these cells at the forefront of regenerative medicine research. The huge promise of this approach is indicated by the spate of papers that soon followed, recording differentiation of human ES cells to neural cell types (neurons, oligodendrocytes and glia), cardiomyocytes, beta cells, osteoblasts, hepatocytes and haematopoietic progenitors. ${ }^{17-23}$ One intriguing possibility, the use of somatic nuclear transfer to create autologous ES cells for therapy, has been widely discussed since the creation of the first cloned animal. ${ }^{24}$ Recently, Hwang et al. have shown that this technique can be applied to human oocytes, resulting in blastocyst formation and derivation of an ES cell line. ${ }^{25}$ The shortage of human ES lines currently available and restrictions in some countries on human ES cell research prevent the whole scientific community from participating in this field. The announcement that seventeen new human ES cell lines will be made freely and widely available ${ }^{26}$ is a great fillip to researchers, though therapeutic use will have to await development of clinical-grade cell lines and resolution of the ethical debates.
Genetic and epigenetic changes can occur following multiple passages of ES cell in culture. ${ }^{27}$ Self-renewal and also simultaneous suppression of the differentiation of ES cells is ensured by a unique network of transcription factors including Nanog, OCT4 and Wnt. Nanog was discovered by expression cloning analysis and named after the mythological Celtic land of the ever young, Tir nan Og. ${ }^{28}$ Oct 4 , or octa-binding factor $3 / 4$, is a member of the Pit-OctUnc family of transcriptional regulators restricted to early embryos. ${ }^{29}$ The Wnt family consists of secreted and extracellular-matrix-associated glycoproteins binding to frizzled seven-transmembrane span receptors. ${ }^{30}$ Recently, DNA microarray, ${ }^{31,32}$ SAGE $^{33}$ and cDNA library analysis ${ }^{34}$ has enabled the identification of global transcription profiles for human ES cells. All demonstrated the existence of gene clusters that are expressed at higher levels in human ES cells than in fully differentiated cells. Human ES cells are characterized by their expression of SSEA3, SSEA4, TRA-160 and TRA-1-81 antigens that are now known to be downregulated during differentiation while several other antigens are induced. ${ }^{34}$

In order to accomplish the transition of human ES cells in the laboratory to clinical application, efforts have been focused on defining the culture conditions needed to derive specific cell phenotypes and their progenitors. The aim is to obtain cells in numbers sufficient for implantation and in conditions of 'good medical practice' (i.e. uncontaminated by foreign cells). The potential hazard of tissue rejection also has to be addressed. In the UK the Medical Research Council has already established a stem cell bank that will provide cell lines to match patients' requirements. Somatic nuclear transfer, or therapeutic cloning, has been used to generate animals with a common genetic composition. ${ }^{35}$ For therapeutic purposes, a nucleus would be taken from one of the patient's somatic cells and transferred into an enucleated donor oocyte, then ES cells would be isolated from the inner cell mass of the cloned embryo; these cells, when implanted, would not be rejected. ${ }^{25}$

Society's current perception of the value and medical potential of ES cells has been influenced by a mixture of media reportage, religion and politics. In some countries, a bias towards research on adult rather than embryonic stem cells arises from objections to the destruction of human embryos necessary for derivation of ES; but in the UK the Human Embryology and Fertilization Authority has authorized the use, and in some instances the creation, of human embryos for therapeutic purposes. Research into adult and embryonic stem cells is not sufficiently advanced for a definitive judgment on whether one source is better than the other as a basis for developing a broad range of stem cell therapies. Each is likely to have its own niche in therapy, and for some conditions a combination of both may prove best. 
Various protocols have proved effective for driving the differentiation of ES cells to particular lineages, including the use of growth factor supplementation of media and genetic modification. In our own centre a robust system has been developed for osteoblast ${ }^{36,37}$ and pneumocyte ${ }^{38-40}$ differentiation from murine and human ES cells employing a defined culture medium. Cell-type-restricted promoters driving expression of either antibiotic resistance genes or fluorophores ${ }^{41}$ make it is possible to separate the desired cell types as the ES cells differentiate. RNA interference to knock down gene expression in ES cells is another advance that produces enriched populations as well as helping elucidate gene function in early development. ${ }^{42,43}$

The ability of cells to interact with stromal cells and repopulate the corresponding niches - a property known as homing-is essential to the success of stem cell transplantation. Signalling molecules such as chemokines and growth factors are thought to be involved in the mechanisms regulating homing and the expression of these increases following tissue injury. Co-culture of embryonic and other stem/progenitor cells with mature cells or tissues is being used increasingly to drive differentiation towards required lineages. ${ }^{44,45}$ Our recent work showed that coculture with murine embryonic pulmonary mesenchyme is an efficient means to upregulate the differentiation of ES cells towards pneumocytes. ${ }^{46}$

\section{THREE-DIMENSIONAL INTERACTIONS}

The normal function of most cells and tissues depends not only on soluble factors but also on spatial interaction with neighbouring cells and with a substratum or extracellular matrix (ECM). Cell-cell and cell-ECM interactions are coordinated by several families of membrane-spanning proteins known as adhesion molecules. These are fundamental to cell adhesion, helping to define 3dimensional cellular organization and also directly participating in cell signalling and controlling cell recruitment, growth, differentiation, immune recognition and modulation of inflammation.

Tissue engineering scaffolds have a dual purpose - to direct morphogenesis in vitro and to maintain the structure and function of the construct as it is integrated with the host tissues after implantation. Various natural and synthetic materials have been used to produce 3-dimensional scaffolds to function as an artificial ECM. Scaffolds for tissue repair ideally should be non-toxic, act as templates for tissue growth in three dimensions, have good biocompatibility, be biodegradable, be able to influence the genes in stem cells to enhance differentiation and proliferation of all the phenotypes required for tissue regeneration, and be capable of interacting specifically with the cell type(s) of interest. ${ }^{47}$ be made bioactive through adsorption with biomolecules, enabling recruitment and adhesion of specific cell types. ${ }^{48-50}$ For routine therapeutic use they will need to conform to regulatory standards and be producible at reasonable cost.

\section{STRATEGIES FOR CLINICAL APPLICATION}

Most clinical applications of tissue engineering must still be regarded as experimental, ${ }^{51}$ although skin substitutes and cartilage grafts have been used successfully for several years. At present, the only reliable cell source for these is autologous cells from the patient. This source has serious limitations in terms of numbers of cells and generation of a viable extracellular matrix. Cloned, immortal, cell lines are capable of proliferating but usually lack the differentiation needed for stable tissue repair. All tissues and organs have a complex interdependence of cell types with an interconnected 3-dimensional architecture. Most tissueengineered constructs involve only one, or at most two, cell phenotypes grown primarily in a 2-dimensional configuration. This compromise in structure limits clinical viability. All tissues/organs have an interpenetrating network of blood vessels to provide nutrition and eliminate waste products. Tissue-engineered constructs at present lack this vital network when they are transplanted. The host tissues must quickly infiltrate the tissue-engineered graft with a blood supply or the cells will die. A major challenge is to achieve angiogenesis rapidly after implantation and maintain a viable nutrient supply as the construct becomes integrated.

Other issues encountered include the maintenance of sterility of a tissue-engineered construct. Most methods used for sterilization of non-living implants and devices, such as gamma-irradiation or autoclaving, kill cells. Sterility must be achieved continuously up to the moment implantation is complete. All of the above factors add to the manufacturing costs and at present limit many tissue engineering applications to exploratory cases. Moreover, since the long-term survivability of tissue-engineering constructs is uncertain, ethical and legal considerations often require restriction to patients in whom no other procedure is available. Use in these 'last-ditch' circumstances makes the viability and success of the new procedures hard to assess. Finally, tissue-engineered products are subject to the same regulatory procedures as non-living biomaterials and devices. At present, only a few products have met these regulatory requirements. Costs and risk/benefit factors are often hard to predict because of the uncertainty of regulatory approval. Further development of tissue engineering, from bench to bedside will be crucial in meeting the healthcare needs of the coming century. 
Note This paper is based on the Ellison-Cliffe Lecture, given at the RSM on 19 October 2004 by Dame Julia Polak.

\section{REFERENCES}

1 Bisceglie V. Uber die antineoplasticsche Immunitat; heterologe Einpflanzung von Tumoren in Huhner-embryonen. Z Krebsforsch 1953;40:122-40

2 Mayhew TA, Williams GR, Senica MA, Kuniholm G, Du Moulin GC. Validation of a quality assurance program for autologous cultured chondrocyte implantation. Tissue Eng 1998;4:325-34

3 Shin-Oka T, Shum-Tim D, Ma P, et al. Tissue-engineered heart valve leaflets - does cell origin affect outcome? Circulation 1997;96:102-7

4 Bjornson CB, Rietze RJ, Reynolds BA, Magli MC, Vecovi AI. Turning brain into blood: a haematopoietic fate adopted by adult neural stem cells in vivo. Science 1999;283:534-7

5 Mezey E, Chandross KJ, Harta G, Maki RA, McKercher SR. Turning blood into brain: cells bearing neuronal antigens generated in vivo from bone marrow. Science 2000;290:1779-82

6 Toma J, Akharvan M, Fernandes KJL, et al. Isolation of multipotent adult stem cells from the dermis of mammalian skin. Nature Cell Biol 2001;3:778-84

7 Blau HM, Brazelton TR, Weimann JM. The evolving concept of stem cells: entity or function? Cell 2001;105:829-41

8 Bianco P, Gehron Robey P. Stem cells in tissue engineering. Nature $2001 ; 414: 118-21$

9 Odorico JS, Kaufman DS, Thomson JA. Multilineage differentiation from human embryonic stem cell lines. Stem Cells 2001;19:193-204

$10 \mathrm{Xu}$ RH, Chen X, Li DS, et al. BMP4 initiates human embryonic stem cell differentiation to trophoblast. Nat Biotechnol 2002;20:1261-4

11 Evans MJ, Kaufman MH. Establishment in culture of pluripotential cells from mouse embryos. Nature 1981;292:154-6

12 Martin G. Isolation of a pluripotent cell line from early mouse embryos cultured in medium conditioned by teratocarcinoma cells. Proc Natl Acad Sci USA 1981;78:7634-8

13 Alexandre H. A history of mammalian embryological research. Int $J$ Dev Biol 2001;45:457-67

14 Martin GR, Evans MJ. Differentiation of clonal lines of teratocarcinoma cells: formation of embryoid bodies in vitro. Proc Natl Acad Sci USA 1975;72:1441-5

15 Thomson JA, Kalishman J, Golos TG, et al. Isolation of a primate embryonic stem cell line. Proc Natl Acad Sci USA 1995;92:7844-8

16 Thomson JA, Itskovitz-Eldor J, Shapiro SS, et al. Embryonic stem cell lines derived from human blastocysts. Science 1998;282:1145-7

17 Zhang SC, Wernig M, Duncan ID, Brustle O, Thomson JA. In vitro differentiation of transplantable neural precursors from human embryonic stem cells. Nat Biotechnol 2001;19:1117-18

18 Mummery C, Ward D, van den Brink CE, et al. Cardiomyocyte differentiation of mouse and human embryonic stem cells. J Anat 2002; 200:233-42

19 Assady S, Maor G, Amit M, Itskovitz-Eldor J, Skorecki KL, Tzukerman M. Insulin production by human embryonic stem cells. Diabetes 2001;50:1691-7

20 Sottile V, Thomson A, McWhir J. In vitro osteogenic differentiation of human ES cells. Cloning Stem Cells 2003;5:149-55

21 Bielby RC, Boccaccini AR, Polak JM, Buttery LDK. In vitro diffentiation and in vivo mineralization of osteogenic cells derived from human embryonic stem cells. Tiss Eng (in press)

22 Schuldiner M, Yanuka O, Itskovitz-Eldor J, Melton DA, Benvenisty N. Effects of eight growth factors on the differentiation of cells derived from human embryonic stem cells. Proc Natl Acad Sci USA 2000;97: $11307-12$
23 Kaufman DS, Hanson ET, Lewis RT, Auerbach R, Thomson JA. Hematopoietic colony-forming cells derived from human embryonic stem cells. Proc Natl Acad Sci USA 2001;98:10716-21

24 Wilmut I, Schnieke AE, McWhir J, Kind AJ, Campbell KH. Viable offspring derived from fetal and adult mammalian cells. Nature 1997; 385:810-13

25 Hwang WS, Ryu YJ, Park JH, et al. Evidence of a pluripotent human embryonic stem cell line derived from a cloned blastocyst. Science 2004;303:1669-74

26 Cowan CA, Klimanskaya I, McMahon J, et al. Derivation of embryonic stem-cell lines from human blastocysts. N Engl J Med 2004;350:1353-6

27 Draper JS, Smith K, Gokhale P, et al. Recurrent gain of chromosomes $17 \mathrm{q}$ and 12 in cultured human embryonic stem cells. Nat Biotechnol 2004;22:53-4

28 Chambers I, Colby D, Robertson M, et al. Functional expression cloning of nanog, a pluripotency sustaining factor in embryonic stem cells. Cell 2003;113:643-55

29 Reim G, Mizoguchi T, Stainier DY, Kikuchi Y, Bran M. The POU domain protein spg (pou2/Oct4) is essential for endoderm formation in cooperation with the HMG domain protein casanova. Dev Cell 2004; 6:91-101

30 Nusse R. Wnts and hedgehogs: lipid-modified proteins and similarities in signaling mechanisms at the cell surface. Development 2003; 130:5297-305

31 Sato N, Sanjuan IM, Heke M, Uchida M, Naef F, Brivanson A. Molecular signature of human embryonic stem cells and its comparison with the mouse. Dev Biol 2003;260:404-13

32 Sperger JM, Chen X, Draper JS, et al. Gene expression patterns in human embryonic stem cells and human pluripotent germ cell tumors. Proc Natl Acad Sci USA 2003;100:13350-5

33 Richards M, Tan SP, Tan JH, Chan WK, Bongso A. The transcriptome profile of human embryonic stem cells as defined by SAGE. Stem Cells 2004;22:51-64

34 Brandenberger R, Khrebtukova J, Thies RS, et al. MPSS profiling of human embryonic stem cells. BMC Dev Biol 2004;4:10

35 Wilmut I, Paterson L. Somatic cell nuclear transfer. Nature 2002;419: 583-6

36 Buttery LD, Bourne S, Xynos JD, et al. Differentiation of osteoblasts and in vitro bone formation from murine embryonic stem cells. Tissue Eng 2001;7:89-99

37 Bielby RC, Pryce RS, Hench LL, Polak JM, et al. Time- and concentration-dependent effects of dissolution products of $58 \mathrm{~S}$ sol-gel bioactive glass on proliferation and differentiation of murine and human osteoblasts. Tissue Eng 2004;10:1018-26

38 Ali N, Edgar AJ, Samadikuchaksaraei A, et al. Derivation of type II alveolar epithelial cells from murine embryonic stem cells. Tissue Eng 2002;8:541-50

39 Rippon HJ, Ali NN, Polak JM., Bishop AE. Initial observations on the effect of medium composition on the differentiation of murine embryonic stem cells to alveolar type II cells. Cloning Stem Cells 2004;6:49-56

40 Samadikuchaksaraei A, Polak JM, Bishop AE. Derivation of type II pneumocytes from human embryonic stem cells. Am J Respir Crit Care Med 2004;169:A87

41 Tai G, Polak JM, Bishop AE, Buttery LD. Differentiation of osteoblasts from murine embryonic stem cells by overexpression of the transcriptional factor osterix. Tissue Engin 2004;10:1456-66

42 Bieberich E, Silva J, Wang G, Krishnamurthy K, Cond BG. Selective apoptosis of pluripotent mouse and human stem cells by novel ceramide analogues prevents teratoma formation and enriches for neural precursors in ES cell-derived neural transplants. J Cell Biol 2004; 167:723-34

43 Matin MM, Walsh JR, Gokhale PJ, et al. Specific knockdown of Oct4 and beta2-microglobulin expression by RNA interference in human 
embryonic stem cells and embryonic carcinoma cells. Stem Cells 2004; 22:659-68

44 Ball SG, Shuttleworth AC, Kielty CM. Direct cell contact influences bone marrow mesenchymal stem cell fate. Int J Biochem Cell Biol 2004; $36: 714$

45 Hwang JH, Yuk SH, Lee JH, et al. Isolation of muscle derived stem cells from rat and its smooth muscle differentiation [corrected]. Mol Cells 2004; 17:57

46 Van Vranken BE, et al. Co-culture of embryonic stem cells with pulmonary mesenchyme: a microenvironment that promotes differentiation of pulmonary epithelium. Tissue Eng (in press)

47 Hench LL, Polak JM. Third-generation biomedical materials. Science 2002;295:1014-17
48 Xynos ID, Edgar AJ, Buttery LD, Hench LL, Polak JM. Ionic products of bioactive glass dissolution increase proliferation of human osteoblasts and induce insulin-like growth factor II mRNA expression and protein synthesis. Biochem Biophys Res Commun 2000; 276:461-5

49 Xynos ID, Hukkanen MV, Batten JJ, Buttery LD, Hench LL, Polak JM. Bioglass 45S5 stimulates osteoblast turnover and enhances bone formation in vitro: implications and applications for bone tissue engineering. Calcif Tiss Int 2000;67:321-9

50 Xynos ID, Edgar AJ, Buttery LD, Hench LL, Polak JM. Geneexpression profiling of human osteoblasts following treatment with the ionic products of Bioglass $45 \mathrm{~S} 5$ dissolution. J Biomed Mater Res 2001;55:151-7

51 Wang W, Vadgama $\mathrm{P} . \mathrm{O}_{2}$ microsensors for minimally invasive tissue monitoring. J R Soy Interface 2004;1:109-17 